TEMAS DE ACTUALIDAD Rev Chil Salud Pública 2015; Vol 19 (1): 69-74

\section{GRUPO DE APOYO TÉCNICO A LOS CENTROS COMUNITARIOS LAS CAÑAS Y EL VERGEL}

\author{
Technical support group for the Las Cañas y El Vergel \\ community centers, Valparaiso, Chile
}

\author{
Grupo de Apoyo Técnico a Centros Comunitarios \\ Las Cañas y El Vergel (Autoría colectiva)*
}

Luego del gran incendio que afectó a Valparaíso los días 12 y 13 de abril de 2014, miles de voluntarios, no solo de la región, concurrieron a ayudar. La sola tarea de retirar las miles de toneladas de escombros ${ }^{1}$ generados significó la movilización de gran número de voluntarios. Muchas universidades e instituciones de educación superior locales suspendieron sus clases, e incluso en algún caso se crearon rápidamente asignaturas de formación general, para retribuir con créditos académicos el esfuerzo. Por otra parte, en varias universidades sus académicos vieron en el incendio un espacio para la realización de investigaciones con diferente nivel de rigurosidad técnica y ética, e incluso, de ejercicios de clases, utilizando como objeto de estudio o de mera práctica a las personas damnificadas.

En un primer momento la ayuda de voluntarios junto con actividades institucionales de centros universitarios resolvió una serie de falencias muy concretas y urgentes, evidenciando de paso la enorme incapacidad estatal para hacerse cargo de la situación. Esta problemática del Estado en todos sus niveles no solo tuvo que ver con la entendible y esperable imposibilidad material de desplegar suficientes recursos y personal para hacerse cargo de las apremiantes necesidades emergentes, sino también con severas falencias en la organización de sus propias instituciones y autoridades, especialmente, en su desinformación de lo que estaba pasando, en la coordinación, además de la conducción de un proceso organizado de respuesta. De hecho, la capacidad de respuesta estatal se enturbió drásticamente por la superposición de actores de escala comunal (Municipio) y regional (Gobierno Regional), que al pertenecer a coaliciones partidistas diferentes, utilizaron la circunstancia para sacar ventajas político-electorales. Durante largo tiempo, la situación podría caracterizarse por sucesivas declaraciones en el sentido de que se estaba trabajando coordinadamente, pese a una serie de decisiones que daban cuenta de una operación por carriles absolutamente separados; por ejemplo, en la distribución de la ayuda, en las acciones de salud implementadas.

En este escenario, surgió y prosperó una intensa actividad de coordinación y acción sin pasar por el Estado. Desde el comienzo fue posible

Aníbal Vivaceta

Escuela de Medicina, Universidad de Valparaíso inteligencia.sanitaria@gmail.com
* Participaron en el Grupo de Apoyo Técnico, en orden alfabético: Sebastián Espinoza, Benjamín Gálvez, Sebastián Godoy, Marcelo González, Yerko González, Rodolfo Jiménez, Marcelo Mieres, Mauricio Salazar, Aníbal Vivaceta. 
ver infinidad de pequeñas iniciativas, ligadas a grupos preexistentes con baja institucionalización o incluso que emergieron a raíz de la propia situación, instalados en diferentes sectores de la zona quemada. La coordinación de estos grupos, cuando existió, se produjo en un nivel muy local y directo, barrial. Algunos de los autores intentaron recopilar y poner a disposición datos de este tipo, como parte de un sistema de monitoreo usando la herramienta de conocimiento distribuido Crowdmap. ${ }^{2}$ Ésta fue, de hecho, una de sus áreas menos exitosa. ${ }^{3}$

Gran parte de la primera respuesta voluntaria se basó en la remoción de escombros, la alimentación y la construcción de viviendas de emergencia, y persistió varias semanas después del evento.

Desde el inicio, también, muchos grupos e instituciones educacionales de lo que podríamos caracterizar como ámbito psicosocial (ONG, federaciones de estudiantes, estudiantes de carreras universitarias, en grupos formales o informales) realizaron labores que consideraban, o al menos declaraban, de apoyo, frecuentemente ligadas a algún nivel de captura de datos, con un bajo nivel de cumplimiento, tanto de lo consagrado en el Manual Esfera -una guía internacionalmente validada para estas circunstancias- como de la legislación nacional, en cuanto a la investigación que involucra a personas. Muchas veces estas intervenciones involucraron a menores, con formatos tipo "dibuja tu experiencia del incendio", sin el mínimo cuidado por los posibles efectos de trauma secundario de tales evocaciones.

También hubo una gran movilización de personas ligadas a lo que comúnmente se denomina actividades artísticas y culturales. Estas actividades en buena medida correspondían a intenciones personales de ir a entregar algo a la gente damnificada, y no a una detección conjunta de necesidades que obedeciera a un diseño de actividades con los actores locales.

Varios meses después del incendio, aún eran muchas las organizaciones y personas que intentaban desplegar acciones que consideraban un apoyo para los afectados; con frecuencia sin ningún involucramiento de éstos en su definición.

\section{ESTIMADAS Y ESTIMADOS:}

Como Centros Comunitarios Las Cañas y El Vergel, queremos manifestar en primer lugar nuestro agradecimiento al apoyo brindado por cada uno(a) de ustedes. Estamos seguros(as) que manos no sobran en virtud del complejo proceso que nos corresponde llevar a cabo y esperamos contar con ustedes en ese camino que nos permita rehabitar nuestros barrios.

Ese camino será largo y extenso, así por lo menos lo muestra nuestra historia como habitantes de la ciudad. A nuestros antepasados les correspondió enfrentar el terremoto de 1906, incendios varios y un sinnúmero de desafíos que hemos enfrentado. Y al parecer tan perdidos no estaban los viejos y viejas que construyeron nuestros barrios, nos legaron una ciudad maravillosa, única y mágica.

Sin embargo, desde hace ya tiempo hemos ido perdiendo a Valparaíso. Nos hemos llenado de edificios, los barrios se desarticulan cada día más y una apatía general respecto a los problemas comunes campea entre nosotros(as). Las políticas públicas y las voluntades políticas parece que hasta acá arriba en el cerro no llegan, como no llegaba casi nadie antes del incendio.

En ese proceso como Centro Comunitario Las Cañas nos pilló el incendio y ha sido complejo. De un momento a otro, pasamos de realizar un trabajo que manejábamos relativamente bien en virtud de los talleres que ejecutábamos, el comedor y especialmente el trabajo con niños y niñas del barrio, a abarcar una gama de funciones que desconocíamos. 
Entonces, de un momento a otro, a partir del incendio, se movió todo. De un momento a otro le interesamos a la TV, a los ministerios, a las ONG, a los políticos, nos solicitan en el Congreso, voluntarios y voluntarias del país llegan, nos ofrecen ahora colocar techos verdes, plantas de reciclaje, talleres de bioconstrucción, relajación, que necesitamos levantar catastros, habitar las quebradas, que funcionen radios comunitarias, que cambiemos leyes, que montemos cooperativas, que los desalojos, que los problemas de los niños y niñas, tercera edad, discapacitados, que mantener el comedor diariamente, repartir mercadería, limpiar, ordenar, coordinar y además hacer malabares para buscar los recursos económicos.

Con este contexto, los riesgos de perderse son altos. Y por momentos nos perdemos. De ahí la necesidad que tenemos de lograr ordenar la casa internamente para poder cumplir la labor que creemos podemos jugar en cuanto canal o instancia de articulación entre los vecinos y vecinas afectados(as) y las instituciones de la ciudad y los aportes individuales.

Necesitamos afinar internamente muchas cosas, de ahí, entre otras razones, la suspensión de la reunión de hoy lunes. Esperamos retomar el lunes 4, para que podamos conversar. Cada uno(a) de ustedes de alguna u otra manera tienen en mente llevar a cabo algún proyecto o idea y no creemos que la suspensión de la reunión de hoy debería entorpecer o detener sus acciones individuales en relación a los temas en los que están trabajando.

Saludos y atentos a sus comentarios, Centros Comunitarios Las Cañas y El Vergel

Dos de los espacios más demandados para funcionar como sedes, nexos, puentes, soporte logístico, representantes, canales de distribución, etcétera, en esta interacción de grupos de ayuda en sus diferentes formas -e incluso en ocasiones de organismos del Estado- ${ }^{4}$ con la población, fueron los centros comunitarios Las Cañas y El Vergel. Sus gestores recibían a diario las más diversas -y a veces difíciles de imaginar-, propuestas de acciones. En muchos casos, los organizadores de las actividades contaban con que el centro correspondiente les proveyera de toda la logística para poder realizar su aporte, aun cuando era evidente la precariedad de recursos luego del incendio; en especial, frente a la tremenda demanda generada.

A mediados de año, se sucedieron amplias reuniones semanales en las que los actores intentaban definir formas de organizarse. Cada reunión contaba con un repertorio parcialmente distinto de actores y en cada una de ellas se definía una nueva forma de organizar el trabajo.

Luego de casi un mes en esa dinámica, los gestores de los centros comunitarios decidieron suspender temporalmente las reuniones y volcarse primero hacia su propia organización. áreas:

Redefinieron la acción en dos grandes

- Actividades comunitarias y culturales

- Apoyo técnico. En este ámbito, se distingue:

- Un rol de comunicaciones.

- Un rol de apoyo técnico en gestión de información y territorio; además de asesoría y evaluación de proyectos de apoyo.

El presenta trabajo se refiere principalmente a este último aspecto.

Para el trabajo de estas comisiones se definen tres criterios generales:

- Solidaridad de clase.

- Que los proyectos apunten a la transformación social.

- Que las acciones y los proyectos redundaran en desarrollo personal para quienes participaran a través de los centros.

Este proceso de reorganización resultó fundamental; tanto por el obligado y necesario reconocimiento al liderazgo del personal local, generado a partir del ejercicio de dicho 
liderazgo en los hechos, como por sus implicancias prácticas de aumento de la efectividad en el trabajo, acoplándose al incremento en los requerimientos, tanto en cantidad como en el tipo de intervenciones.

El grupo original estuvo conformado por miembros institucionalmente ligados a los propios centros comunitarios Las Cañas y El Vergel, al espacio Santa Ana, a las escuelas de Medicina y Odontología de la Universidad de Valparaíso (UV) y a la Escuela de Salud Pública de la Universidad de Chile (ESP-UCh).

Más allá de los vínculos de varios participantes del grupo de apoyo técnico con instituciones académicas, su participación hacia el colectivo se ha realizado desde el inicio, no en calidad de representantes de dichas instituciones, sino como una responsabilidad personal hacia éste.

Una de las primeras propuestas analizadas fue la de profesores de la Escuela de Arquitectura de la Universidad de Santiago (USACH), para realizar un trabajo de estudiantes de cuarto año, desde la perspectiva de la metodología de aprendizaje en servicio. A pesar de la reticencia inicial, debida a la distancia geográfica y a experiencias previas con escuelas de arquitectura locales -más preocupadas de la glamorosa opinión respecto de planificación urbana en los espacios definidos por las autoridades, que al trabajo sobre las necesidades locales-, finalmente el grupo acogió la propuesta. El factor fundamental para hacerlo fue la permanente disposición de estos estudiantes a no avanzar ni un paso sin consultarlo con las personas afectadas.

Aunque ausente por lo general de las reuniones ordinarias semanales del grupo, debido a su localización algo distante, su coordinador se incorporó a la dinámica del Grupo de Apoyo Técnico. El correo electrónico y WhatsApp han permitido su participación a pesar de la distancia física.

De esta manera, el trabajo del equipo de apoyo técnico fue decantando sus enfoques hacia dos frentes complementarios:

- Por una parte, el grupo recibe semanalmente propuestas de diferentes actores para trabajar con los centros comunita- rios, escucha sus presentaciones y orienta su adecuación a las condiciones definidas por los miembros de los centros. Generalmente, se llega a una reformulación que posteriormente es presentada a éstos. En otras ocasiones, los grupos desisten por diferentes razones, entre las que se cuenta reticencia hacia el mecanismo de trabajo y restricciones de tiempo en el caso de trabajos académicos.

- Por otra parte, el grupo ha iniciado un trabajo de levantamiento y sistematización de datos sobre el territorio cubierto por ambos centros, sustentado en la actividad de los estudiantes de arquitectura USACH y de Medicina UV; además de la recopilación de datos generados por otros actores, por ejemplo, estatales. La expectativa compartida es que gradualmente los actores locales puedan desarrollar las capacidades tecnológicas necesarias para interrogar estos datos autónomamente. Esto debería servir para fortalecer las posiciones de los pobladores en sus negociaciones frente a los organismos gubernamentales y para favorecer la generación por parte de ellos de interpretaciones de su propia situación, facilitando la coordinación y organización local. La representación espacial, tanto en dos dimensiones (mapa), como en tres (maqueta), se visualiza como una herramienta fundamental para permitirles la comprensión de la situación e incluso para generar nuevo conocimiento al interactuar con dichas representaciones. La reciente incorporación al grupo de apoyo técnico de un geógrafo -además, criado en el sector-, está ampliando la capacidad de procesar datos espacializados.

No perdemos de vista la observación de David Harvey, en una reciente visita a nuestra experiencia: "La acción política depende más de las emociones que de los datos". Sin embargo, pensamos que sin apropiarse de ellos -de su uso, de su generación- los pobladores tradicionalmente marginados no tienen oportunidad de interpelar a las instituciones y autoridades respecto de los recursos que éstas manejan. 
Actualmente, el grupo de apoyo técnico se ha consolidado como un espacio que alivia la presión de iniciativas externas a los ya sobredemandados miembros de los centros comunitarios. Junto con ello, cristalizan gradualmente las propuestas de ordenamiento territorial, saneamiento ambiental, construcción colectiva -sistematizadas por los estudiantes de arquitectura en interacción con los integrantes de los centros a través de sucesivas presentaciones, seguidas de su discusión-. Un detalle puede dar cuenta de diferencias fundamentales con la forma de concebir la participación desde el punto de vista tradicional del Estado: ambos centros comunitarios se encuentran a una distancia suficiente como para impedir que los mismos actores puedan participar sucesivamente en las presentaciones de uno y otro. La necesidad de optimizar la presencia de los estudiantes y profesores venidos desde Santiago, implica decidir entre realizar una presentación conjunta a ambos colectivos o reuniones separadas en cada territorio. La lógica de instituciones y autoridades lleva necesariamente a optar por lo primero, para permitir que las autoridades estén siempre presentes. La opción de realizar actividades por separado -a pesar de que ambos centros trabajan de hecho, en conjunto- apunta a la idea de que los temas de cada territorio se discutan en cada uno de ellos. La imposibilidad de que los integrantes del grupo de apoyo técnico puedan estar en ambas partes a la vez no significa una pérdida, pues nadie es imprescindible. Esta simple señal puede dar cuenta de quiénes son los actores prioritarios en este trabajo.

Actualmente, identificamos dos desafíos fundamentales e interrelacionados: Debemos encontrar formas de superar las tradicionales visiones y prácticas ligadas al saber experto. La complejidad de las tareas emprendidas facilita darse cuenta de que no hay una sola disciplina -arquitectura, urbanismo, sociología, psicología social, salud pública, geografía- que pueda arrogarse la supremacía técnica en este debate. Es el fundamento habitual de la multidisciplinariedad o la interdisciplinariedad y las disquisiciones sobre ambas. Más difícil resulta, en cambio, vencer años de tradiciones académicas e institucionales que descartan el saber local a la hora de reconocer experticias. No nos referimos a declaraciones de principios, pues hasta los discursos de autoridades muy poco participativas los mencionan. Nos referimos al acto diario de reconocer en igualdad de condiciones el saber de los actores locales, además de su primacía a la hora de definir hacia dónde vamos, simplemente porque el resultado de la acción colectiva los afectará de manera muy distinta y directa. Más allá de nuestras convicciones e incluso de nuestras experiencias vitales, esto implica un ejercicio personal de des-aprendizaje, pues las prácticas que consolidan la separación expertos/legos están muy arraigadas y nos exponen permanentemente a reproducir lo que criticamos.

Un aspecto particularmente desafiante es el de la traducción de lenguajes técnicos, más notorio aún dada la participación de estudiantes. En efecto, parte significativa del estudio de una carrera tiene que ver con el aprendizaje de un tecnolecto. Los estudiantes requieren ejercitar un proceso inverso a la hora de comunicarse con otros actores no hablantes de dicho tecnolecto. Se trata, en cierto sentido, de abrir en conjunto con quienes no dominamos el lenguaje de una cierta disciplina, las cajas negras de Latour. Este proceso todavía ocupa buena parte de nuestras preocupaciones y hasta ahora hemos avanzado en una estrategia de discusión colectiva, que reconozca que no es una situación bipolar expertos/no expertos, sino una situación abierta, donde cada uno de nosotros sabe un poco e ignora mucho, pero colectivamente todos sabemos mucho más. Entendemos a los miembros de los centros comunitarios como mediadores/traductores fundamentales de este trabajo al resto de la población de estos territorios.

La interacción con esa otra población, que participa esporádicamente en algunas actividades de los centros o que no participa, también es un área de permanente reflexión. El desafío de incorporarla a un trabajo colectivo no solo tiene que ver con su relación previa con los miembros de los centros y las expectativas que de éstos pueden hacerse, sino también con otras variables, como los recursos oficiales disponibles. En efecto, cualquier 
iniciativa de acción colectiva choca de frente con la concepción individualista que ha inspirado la mayor parte de la respuesta estatal. Se han asignado importantes volúmenes de recursos a un sistema de subsidios centrados en cada familia afectada.

No hay un impedimento explícito a formas de organización para llegar a respuestas colectivas, como podría ser la redistribución de pequeños territorios - de forma de combinar la liberación de espacios comunes con una razonable densificación de la construcción-, que permita además obras colectivas de aseguramiento de laderas, similar a lo hecho en la ciudad de Medellín. Sin embargo, toda la operacionalización de la política de recuperación y reconstrucción apunta a la acción por separado. Algunos operadores clave, como quienes tuvieron a cargo las políticas de reconstrucción desde la delegación presidencial, fueron bastante más explícitos en descalificar y desincentivar la organización territorial, privilegiando las políticas tradicionales de participación informativa a la hora de aplicar los escasos recursos para espacios colectivos. Cualquier abordaje colectivo propuesto debe luchar con la oferta tácita o explícita de soluciones más rápidas al actuar individualmente. No olvidemos tampoco que se trata de sectores con una alta proyección inmobiliaria, dado su reciente cambio de uso de suelo. Las políticas de reasentamiento/relocalización han tenido que ver con ello, sin duda. El de- sarrollo de propuestas colectivas debe luchar siempre, entonces, con múltiples vectores que impulsan las cosas hacia lo opuesto.

La relación con este Estado, que favorece la relocalización y las soluciones individuales para quienes se quedan, es un último desafío que queremos compartir. Nuestra intención no es estar bien preparados para cuando las autoridades se dignen pedir una opinión. La expectativa de nuestro trabajo es crear un escenario donde los propios pobladores, con apoyo de los técnicos, puedan convocar a los actores institucionales, no para darles la opinión local sobre unos temas dispersos definidos desde arriba, sino para discutir de igual a igual los problemas identificados por los propios afectados, las soluciones propuestas desde esa experiencia y llegar a acuerdos que no sean la mera modulación de una decisión gubernamental.

\section{NOTAS}

1. Para hacernos una idea, baste decir que la Municipalidad continuaba retirando la cantidad de dos mil toneladas diarias cuando obtuvimos el dato, cuarenta días después del incendio.

2. www.ushahidi.com

3. A diferencia, por ejemplo, de la vigilancia epidemiológica.

4. Y éstos en ocasiones ligados a empresas privadas del área de la construcción. 